\title{
Assessment of Psychosocial Needs among Internally Displaced Persons (IDPS) In Maiduguri Based On the Humanitarian Emergency Settings Perceived Needs Scale (HESPER)
}

\author{
Victor Chidi Onyencho ${ }^{1}$, Pindar Sadique Kwajaffa ${ }^{1}$, Wakawa Ibrahim Abdu ${ }^{1}$, \\ Mshelia Anthony $\mathrm{Ali}^{2}$, Ogualili Placidus ${ }^{2}$ Jidda Said Mohammed ${ }^{1}$, \\ Wakil Musa Abba ${ }^{1}$ \\ ${ }^{I}$ Mental Health Department, College of Medical Sciences, University of Maiduguri. Borno State, Nigeria. \\ ${ }^{2}$ Mental Health Department, Federal Neuropsychiatric Hospital, Maiduguri, Borno State, Nigeria.
}

\begin{abstract}
The current insurgency in the north-eastern Nigeria has brought worldwide attention to the plight and needs of the displaced persons. This study aims to assess the psychosocial needs and services available at the selected Internally Displace Person's camps in Maiduguri-based on (HESPER). This is a descriptive, crosssectional study using multistage sampling techniques; cluster sampling techniques was used to select nine IDPs camps and finally 450 household heads or family representatives through systematic sampling techniques. Food (91.6\%), shortage of place to live in $(85.1 \%)$, shortage of good enough clothes, shoes, bedding or blankets (88.3\%), lack of easy and safe access to a clean toilet (81.1\%), shortage of soap, water, suitable place to wash, sanitary materials $(81.8 \%)$ were reported as a serious problem by majority of the displaced persons. Primary needs should be address first before secondary and tertiary needs. Therefore, government should ensure emergency setting psychosocial services are being conducted by the NGOs according to their mandates to prevent misplace priority and to avoid duplication of functions among the humanitarian actors
\end{abstract}

Keywords: Internally Displaced Persons, North Eastern Nigeria, Psychosocial Services.

\section{INTRODUCTION}

The ongoing crisis has generated an estimated 13,000 - 17, 500 deaths, and resulted in massive population displacement arising from fear of insurgents, assaults, destruction of property, and loss of livelihood (Human Right Watch, 2014; Amnesty International, 2014; Walker, 2012). The insurgency has reportedly forced 1.5 million people to flee to other parts of the country; at least 150,000 have taken refuge in neighboring Chad, Niger, and Cameroon. Government counter-insurgency operations have also contributed to the insecurity and displacement, both in the north-east and in neighboring countries (Internal Displacement Monitoring Centre, 2014). According to International Organisation for Migration 'IOM" (2015) Displacement Tracking Matrix program (DTM), Borno State had the highest number of the IDPs $(1,002,688)$ followed by Yobe State $(125,484)$ and Adamawa State $(113,437)$.

The capacity to provide psychosocial support to the affected population by the various governmental actors involved in humanitarian assistance, coordinated by National Emergency Management Agency (NEMA) and State Emergency Management Agency (SEMA) in the affected states has been overstretched due to the magnitude of the problems, poor coordination, corruption and the leaned resources.

In June 2015, the International Non-Governmental Organisation Forum in Nigeria performed an assessment in order to evaluate the needs of the displaced population, identify gaps in support and recommend action points. The conclusion of this exercise highlighted that the most urgent needs of the affected and displaced population were Food, Protection, and Livelihoods, while needs at the critical stage included Health, Nutrition, Shelter/NFIs, Education, WASH, and Psychosocial Support (INGO Forum in Nigeria, 2015).

In another study, psychosocial needs and resilience factor at individual and family levels were the same but in different proportions, the majority expressed negative feelings and few reported positive feelings. Factors associated with these negative feelings are; the desire or willingness to go home and the uncertainty associated with the return or lack of means to go home, loss, lack of basic and social amenities (food, shelter), and separation of family members due to displacement and lack of schooling for their children. A significant number of the respondents confirmed the presence of people with severe mental disorders both in the 'official' and the 'unofficial' camps. Most of the mental health issues reported were most likely pre-existing. Some cases might be due to epilepsy, while others are a form of psychosis. It is possible that most of the cases might be relapses due to a shortage of medications as a consequence of displacement (IOM-DTM program, 2015). 
World Health Organization and King's College London (2011) through Humanitarian Emergency Setting Perceived Needs Scale (HESPER) gives an overview of the serious problems reported in a study; 'Income or livelihood' was the area which was perceived as serious problem by the largest number of participants, and was also rated by the largest number of participants as one of their three most serious problems. Other areas which were commonly rated as one of participants' three most serious problems, and were also perceived as serious problem by a large number of participants, were 'Food', 'Physical health', 'Place to live in', 'Being displaced from home', 'Separation from family members', 'Clothes, shoes, bedding, or blankets', and 'Alcohol or drug use in your community'. Other serious problems which were named commonly by participants were an issue with resettlement. Men and women had a similar number of serious problems overall.

There has always been a need for the development of a humanitarian charter to cater for this need, sphere project launched in 1997, produced a "Humanitarian Charter" and identified "Minimum Standards" for relief operations in disasters, in the areas of water supply and sanitation, nutrition, food aid, shelter and health services. Mental Health and Psychosocial Support (MHPSS) have already been discussed as a standard in the 2004 Sphere Handbook on Mental and social aspects of health, covering standards and indicators for the acute emergency phase of a humanitarian crisis (The Sphere Project, 2004; Inter-Agency Standing Committee, 2007).

On detailed literature search, we could not find any study assessing the level of psychosocial support for displaced persons in Maiduguri. The only study that was done in respect of psychosocial need assessment by IOM was in Adamawa state and the main focus was on resilience factors. Considering the ongoing humanitarian disaster in the North Eastern Nigeria, this study was conducted to assess the psychosocial needs and services available at the displaced person's camps, based on the humanitarian emergency setting perceived needs.

\section{METHOD}

\section{Design and Setting}

This is a descriptive, cross-sectional study conducted at the IDPs camps in Maiduguri, Borno State, Nigeria.

\section{Sampling Techniques}

Multi-stage sampling techniques were employed; cluster sampling techniques used to select 9 Internally Displaced Persons (IDPs). Four hundred and fifty household heads or the family representative residing in the camps were selected at an interval of 9 through systematic sampling techniques.

\section{Participants}

The minimum sample size was computed using a prevalence of 50\% (HESPER, 2011), and 95\% confidence interval with a corresponding critical value $(\mathrm{Z})$ of 1.96 and 0.05 degree of precision was used. This yielded a minimum sample size of 384 respondents but in order to increase the power of the study 450 participants was assessed.

\section{Instruments}

World Health Organization \& King's College London (2011) developed Humanitarian Emergency Settings Perceived Needs Scale (HESPER) to fill several gaps in the humanitarian field. HESPER aims to provide a quick and reliable way of assessing the perceived serious needs of people affected by large-scale humanitarian emergencies such as war, conflict or major natural disaster. One-week test-retest reliability for the full scale was 0.961 in Jordan, and 0.773 in Nepal. Inter-rater reliability was 0.998 in Jordan, 0.986 in Haiti, and 0.995 in Nepal. Correlations with selected items of the World Health Organisation Quality of Life (WHOQOL)100 were as predicted, suggesting criterion (concurrent) validity in the three tested sites.

\section{Ethical Clearance}

Ethical clearance was sought from both Borno state ministry of health, the ministry coordinates Borno state government activity in various IDPs camps within the state through SEMA, and NEMA, an agency that coordinates federal government activity within the camps after the protocol was found to be in substantial compliance with the Declaration of Helsinki for research in human subjects.

\section{Analysis}

Descriptive statistic was employed for the analysis of the data. 


\section{RESULTS}

Heads of families or family representatives of IDPs residing in various camps in Maiduguri were assessed using HESPER. Demographic characteristics of the participants were as follows in the table below.

Table 1: Showing Demographic Characteristics of the Participants.

\begin{tabular}{|l|l|c|}
\hline Variables & N & \% \\
\hline Age: & \multicolumn{2}{|c|}{ Mean age (44) yrs; SD (7.2) } \\
\cline { 2 - 3 } Adolescents (13-17 yrs) & 5 & 0.11 \\
Adulthoods (18-64yrs) & 423 & 93.7 \\
Older Adults (65 and above) & 22 & 4.8 \\
\hline Gender: & & \\
Male & 302 & 67.1 \\
Female & 148 & 32.9 \\
\hline Marital status: & & \\
Married & 349 & 77.6 \\
Single & 44 & 9.8 \\
Separated & 20 & 4.4 \\
Widow/widower & 29 & 6.4 \\
\hline Employment status: & & \\
Employed & 63 & 14 \\
Unemployed & 376 & 83.6 \\
\hline Educational status: & & \\
M.Sc & 1 & 0.2 \\
B.Sc & 1 & 0.2 \\
NCE/OND & 11 & 2.4 \\
SSCE & 41 & 9.1 \\
Below SSCE & 166 & 36.9 \\
Islamic Education & 215 & 47.8 \\
\hline
\end{tabular}

Participant's age ranges between 17-80 years, mean age (X) was 44 and standard deviation (SD) 7.2, IDPs within the adult's age was the highest group that participated in this study $93.7 \%$. Male dominated the group $67.1 \%$ while female were $32.9 \%$. Most of the participants were married $77.6 \%$, the majority were unemployed $83.6 \%$. A high number of the participants went to Islamic school $47.8 \%$ while 36.9 have below SSCE. The length of time of displacement was assessed, $8.2 \%$ were displaced less than one year ago, $67 \%$ were displaced less than two years ago and $19.7 \%$ were displaced more than two years ago.

Table 2: Showing serious problems perceived by the IDPs in the camps

\begin{tabular}{|l|l|l|l|l|l|l|}
\hline & Perceived Serious Problems as results of: & \multicolumn{2}{l|}{$\begin{array}{l}\text { No serious } \\
\text { problem }\end{array}$} & \multicolumn{2}{l|}{$\begin{array}{l}\text { Serious } \\
\text { problem }\end{array}$} \\
\cline { 3 - 7 } & & $\mathbf{N}$ & $\boldsymbol{\%}$ & $\mathbf{N}$ & $\%$ \\
\hline 1. & Inadequate drinking water & 159 & 35.3 & 291 & 64.7 \\
\hline 2. & Inadequate food supply & 37 & 8.2 & 412 & 91.6 \\
\hline 3. & Shortage or lack of suitable place to live in & 65 & 14.4 & 383 & 85.1 \\
\hline 4. & Lack of easy and safe access to a clean toilet & 83 & 18.4 & 365 & 81.1 \\
\hline 5. & $\begin{array}{l}\text { Shortage or lack of soap, water, suitable place to wash, sanitary } \\
\text { materials }\end{array}$ & 80 & 17.8 & 368 & 81.8 \\
\hline 6. & Shortage of good enough clothes, shoes, bedding or blankets? & 47 & 10.7 & 396 & 88.3 \\
\hline 7. & Inadequate income, money or resources to live & 102 & 22.7 & 336 & 74.4 \\
\hline 8. & Physical illness, injury, disability & 102 & 22.7 & 336 & 74.4 \\
\hline 9. & $\begin{array}{l}\text { Inadequate health care for yourself? For example, treatment or } \\
\text { medicines, health care's during pregnancy or childbirth. }\end{array}$ & 91 & 20.2 & 299 & 66.4 \\
\hline 10. & $\begin{array}{l}\text { Feeling very distressed? For example, very upset, sad, worried, } \\
\text { scared, or angry. }\end{array}$ & 80 & 17.8 & 356 & 79.1 \\
\hline 11. & $\begin{array}{l}\text { Feeling you or your family are not safe or protected where you } \\
\text { live now? For example, because of conflict, violence or crime in } \\
\text { your community, city or village. }\end{array}$ & 258 & 57.3 & 181 & 40.2 \\
\hline 12. & $\begin{array}{l}\text { Inability of your children to attend school or are not getting a good } \\
\text { enough education }\end{array}$ & 174 & 38.7 & 234 & 52.0 \\
\hline
\end{tabular}




\begin{tabular}{|l|l|l|l|l|l|}
\hline 13. & $\begin{array}{l}\text { Inability to care for family members who live with you? For } \\
\text { example, young children, elderly, physically or mentally ill, } \\
\text { disabled family members }\end{array}$ & 116 & 25.8 & 312 & 69.3 \\
\hline 14. & $\begin{array}{l}\text { Feeling you are not getting enough support from people in your } \\
\text { community? For example, emotional support or practical help. }\end{array}$ & 126 & 28.0 & 320 & 71.1 \\
\hline 15. & Been separated from family members & 72 & 16.0 & 346 & 76.9 \\
\hline 16. & Been displaced from your home country, city or village & 26 & 5.8 & 417 & 92.7 \\
\hline 17. & $\begin{array}{l}\text { Feeling you do not have enough information? For example, } \\
\text { information about the aid that is available at the camp or } \\
\text { information about what is happening in your hometown. }\end{array}$ & 14.2 & 359 & 79.8 \\
\hline 18. & $\begin{array}{l}\text { Inadequate aid? For example, because you do not have fair access } \\
\text { to the aid that is available, or because aid agencies are working on } \\
\text { their own without involvement from people in your community. }\end{array}$ & 51 & 11.3 & 337 & 74.9 \\
\hline 19. & $\begin{array}{l}\text { Feeling you do not feel respected or you feel humiliated? For } \\
\text { example, because of the situation, you are living in, or because of } \\
\text { the way people treat you. }\end{array}$ & 227 & 50.4 & 195 & 43.3 \\
\hline 20. & $\begin{array}{l}\text { Feeling you are not able to move between places? For example, } \\
\text { going to another village or town. }\end{array}$ & 164 & 36.4 & 277 & 61.6 \\
\hline 21. & Feeling you have too much free time in the day & 115 & 25.6 & 269 & 59.8 \\
\hline
\end{tabular}

Heads of the families or their representatives were asked about the availability of drinkable water in the camps, 291 (64.7) reported that they were having a serious problem with the drinkable water in the camps, inadequate food supply was equally reported by a high number of respondents $412(91.6 \%)$. Shortage or lack of a suitable place to live was also reported as a serious problem by $383(85.1 \%)$ of the participants. Lack of easy and safe access to a clean toilet was perceived as a serious problem by $365(81.1 \%)$ of the Internally Displaces Persons (IDPs), shortage or lack of soap, water, suitable place to wash, sanitary materials was seen as a serious problem by high number of the participants $368(81.8 \%)$, shortage of good enough clothes, shoes, bedding or blankets were reported as a serious problem by 396 (88.3) of the IDPs. Inadequate income, money or resources to live on were seen as a serious problem by $336(74.4 \%)$, similarly, physical illness, injury, and disability among the IDPSs were reported as a serious problem $336(74.4 \%)$. Inadequate healthcare for yourself such as treatment, medicines, care's during pregnancy or childbirth was also seen as a serious problem $299(66.4 \%)$ within the camps, feeling very distressed e.g, very upset, sad, worried, scared, or angry was reported as a serious problem among the participants, inability of your children to attend school, or are not getting a good enough education was moderately reported as a serious problem by the participants $234(52.0 \%)$.

Inability to care for family members who live with you, such as young children, elderly, physically or mentally ill, disabled family members was seen as a serious problem by 312 (69.3\%) of the participants. Feeling you are not getting enough support like emotional or practical support within the IDPs community was reported as a serious problem $320(71.1 \%)$. Been separated from family members was reported as a serious problem by the participants $346(76.9 \%)$, also, been displaced from your city or village was highly reported as a serious problem by the IDPs 417 (92.7\%). Feeling you do not have enough information, such as information about the aid that is available at the camp or information about what is happening in your hometown was seen as a serious problem 359 (79.8\%), Inadequate aid; because you do not have fair access to the aid that is available, or because aid agencies are working on their own without involvement from people within the camp was reported as a serious problem by 337 (74.9\%) of the participants. Feeling you are not able to move between places, such as going to another village or town was seen as a serious problem by the IDPs $277(61.6 \%)$, lastly, feeling you have too much free time in the day was seen as a serious problem by $269(59.8 \%)$ of the participants.

On the other hand, feeling you or your family are not safe or protected where you live now was not seen or reported as a serious problem by $258(57.3 \%)$ of the IDPs. And feeling you do not feel respected or you feel humiliated because of the situation you are living in, or because of the way people treat you by the camp officials was not seen as a serious problem by $227(50.4 \%)$ of the participants.

\section{DISCUSSION}

The future of IDPs in North Eastern Nigeria remains bleak in the presence of this current economic recession and dismal budgetary allocation to rebuild the region by the federal government. In this index study, psychosocial needs among internally displaces persons were assessed based on HESPER, perceived need with sixty percent and above was considered high to be included in our discussion. Inadequate food supply within the IDPs was a serious problem that needed attention as reported by $91.6 \%$ participants, a percentage that is considered to be extremely high. This study was in line with the findings of previous studies among IDPs within and outside Nigeria that the most urgent needs of the displaced population were food, protection, and livelihood 
(INGO Forum in Nigeria, 2015; WHO \& King's College, 2011). Accommodation problem is a recurrent index in any crisis situation worldwide, Shortage or lack of a suitable place to live was reported as a serious problem by $85.1 \%$ of the participants in this present study. This finding agreed with previous studies that found shelters as a factor associated with negative feelings among the displaced population (IOM-DTM, 2015; WHO \& King's College, 2011). Due to the inflow of people from various communities in Borno states into IDPs camps in Maiduguri the state capital and the only city that was considered as the safest at the peak of the insurgency. Lack of easy and safe access to a clean toilet was a serious problem within the camps as reported by $81.1 \%$ of the participants. Our finding was similar to the finding of WHO and King's College (2011) among the displaced population.

In an emergency situation like the current humanitarian crisis in north-eastern Nigeria, putting a structure that will be up to standard together in the camps is not always an easy task for government and nongovernmental organizations because of the urgency. Therefore, shortage or lack of soap, water, a suitable place to wash, sanitary materials will always be noted as reported by $81.8 \%$ of the IDPs. This study was in tandem with a similar study by INGO Forum in Nigeria (2015). Within a helpless population like IDPs, shortage of good enough clothes, shoes, bedding or blankets is always common as $88.3 \%$ of the IDPs reported it as a serious problem. This finding agrees with the previous study by WHO and King's College (2011) that found clothes, shoes, bedding or blanket as a serious problem in their study. Inadequate income, money or resources to live on were seen as a serious problem by $74.4 \%$ of the participants in this index study, this finding was in support of the earlier study that reported similar finding (WHO \& King's College, 2011; INGO Forum in Nigeria, 2015).

Similarly, physical illness, injury, and disability among the IDPSs were reported as a serious problem, $74.4 \%$ of the IDPs attested to this fact in this index study. This study agrees with WHO \& King's College (2011) study that found physical health as a serious problem in their study. In many internally displaced camps, inadequate healthcare, shortage of medicines, poor care's during pregnancy or childbirth was often reported, $66.4 \%$ of the participants perceived the above psychosocial services as a serious problem in our study. This finding supported the study of INGO Forum in Nigeria (2015) that included psychosocial support as one of the needs of IDPs as health, psychosocial support services and so on.

Within the IDPs camps ones is incapacitated on so many things, inability to care for family members who live with you, such as young children, elderly, physically or mentally ill, disabled family members often occur, $69.3 \%$ of the participants reported that they are unable to cater for their loved ones as a result of the displacement. Also, been separated from family members was reported as a serious problem by the participants $76.9 \%$, and $92.7 \%$ of IDPs reported that been displaced from their city or village was a serious problem. Based on the above findings, inability to perform one's obligation due to the displacement from one's city or village has done a lot of harm than good to the displaced persons. This finding concurred with other similar studies that factors associated with negative feelings are a separation of family members due to displacement, being displaced from home (IOM-DTM Program, 2005; WHO \& King's College, 2011).

In an environment where ordinary stress and traumatic stress has become the order of the day, each survivor has one or two thing to deal with personally, even the humanitarian workers are overstretched, emotional or practical support might not be adequate. In this study, $71.1 \%$ of the participants reported that getting emotional or practical support was a serious problem, this finding agrees with INGO Forum in Nigeria (2015) that psychosocial support services are one of the urgent need of the IDPs. Channels of flow of information might not be well established in an emergency setting, $79.8 \%$ of the participants reported this as a serious problem. This study agreed with the finding of the previous study that being displaced from which might lead to miscommunication about what is going on their hometown (WHO \& King's College, 2011).

Inadequate aid was reported as a serious problem by $74.9 \%$ of the participants, a percentage that is significantly high and calls for concerns. Aid cuts across various psychosocial support indicators that could be perceived as relief by the IDPs. This finding agreed with the study of INGO Forum in Nigeria (2015) that reported urgent needs of the displaced population were giving aid such as food, protection, means of livelihood etc. Also, movement restriction could be observed within the IDPs camps due to the fear of the unknown, $61.6 \%$ of the participants reported it as a serious problem.

\section{CONCLUSION AND RECOMMENDATION}

Base on the above findings, psychosocial needs among IDPs in Maiduguri-based on HESPER will be classified according to Abraham Maslow's hierarchy of needs in other to give the needs necessary attention it required. Firstly, biological and physiological needs of the IDPs in this study are; food, water, sanitary materials, healthcare services, accommodation, lack of soap, bedding or blanket. Secondly, safety needs of the participants are; easy and safe access to a clean toilet, a suitable place to wash, good clothes and shoes. Thirdly, belongingness and love needs are; separation from family members, getting emotional or practical support and inadequate aid. Fourthly, esteem needs are; inability to care for family members who live with the displaced persons, lack of good channels of information and movement restriction. Lastly, self-actualization needs are the 
inability to perform one's obligation due to displacement. It is therefore recommended that government at all levels, NGOs, Communities, and the individual should have a proactive role in the recovery process, including planning and constructing environmental conditions to promote successful resolution and rehabilitation of the IDPs. Maiduguri as of today is flooded with various NGOs with different mandates, government should ensure that NGOs operates according to their mandates optimally in those areas of needs that has been highlighted by Abraham Maslow hierarchy of needs, primary needs should be address first before secondary and tertiary needs to avoid misplace of priority in the psychosocial need intervention for the IDPs and to avoid duplication of functions among the humanitarian actors. Also, for those higher needs of displaced person according Abraham Maslow hierarchy of needs such as belongingness and love needs, esteem needs and self actualization needs, it should be incorporated into psychosocial need intervention in the displacement camps, in addition, United Nations (UN), International and local NGOs should adopt some of these higher needs as their core mandate because human/psychosocial needs assessment cannot be completely done without taking some of this higher needs into consideration.

\section{LIMITATION}

Study of this nature cannot be complete without having its own limitations, this is a project that should involve a large sample but because of financial difficulty, administrative bureaucracy and lack of synergy between government official and security personnel's we could not embark on a large sample size study and this could affect the generalization of the findings.

Detail of selected camps for displaced persons in Maiduguri Metropolis

\begin{tabular}{|c|c|c|c|c|}
\hline & Camps & $\begin{array}{l}\text { No. of } \\
\text { families }\end{array}$ & $\begin{array}{l}\text { No. of } \\
\text { individuals }\end{array}$ & Organization present in the camps \\
\hline 1. & $\begin{array}{l}\text { Christian Association of } \\
\text { Nigeria Centre }\end{array}$ & 932 & 7,897 & NEMA, SEMA, UNICEF, ICRC \\
\hline 2. & $\begin{array}{l}\text { Arabic Teachers } \\
\text { College }\end{array}$ & 1,568 & 8,034 & Save the Children, UNICEF, Red Cross \\
\hline 3. & Teachers Village & 3,479 & 9,268 & $\begin{array}{l}\text { UNICEF, MSF, Nigeria Red Cross, UNHCR, } \\
\text { Save the Children, PSM, IOM }\end{array}$ \\
\hline 4. & NYSC Camp & 1,100 & 4730 & $\begin{array}{l}\text { NEMA, SEMA, UNICEF, IOM, UNHCR, } \\
\text { UNFPA, IRC, WHO, CMAM, AAH, BOSEPA, } \\
\text { WEP, ICRC, Save the Children }\end{array}$ \\
\hline 5. & Mogolis Camp & 300 & 2,300 & $\begin{array}{l}\text { UNICEF, LUASA, SEMA, NEMA, Save the } \\
\text { Children, Lake Chad }\end{array}$ \\
\hline 6. & Bakasi Camp & 832 & 5,748 & $\begin{array}{l}\text { NEMA, SEMA, USAID, UNICEF, IOM, } \\
\text { UNHCR, Red Cross, Action Against Hunger }\end{array}$ \\
\hline 7. & $\begin{array}{l}\text { Shehu Sanda Kyarimi } \\
\text { Camp }\end{array}$ & 568 & 2,028 & UNICEF, Red Cross, Save the Children IOM \\
\hline 8. & Goni Kachallari Camp & 500 & 5014 & Red Cross, UNICEF, IOM, WHO \\
\hline
\end{tabular}

\section{REFERENCES}

[1] Human Rights Watch. (2014). World Report: Nigeria. Washington: Human Rights Watch.

[2] Amnesty International. (2014/2015). Amnesty International Report Nigeria. Washington: Amnesty International.

[3] Walker, A. (2012). What is Boko Haram? Washington: United States Institute of Peace.

[4] International Displacement Monitoring Centre 'IDMC', (2014). Nigeria: Multiple displacement crises overshadowed by Boko-Haram. Retrieved on August 4th, 2016 from: http://www.internaldisplacement.org/publications/

[5] International Organisation for Migration 'IOM' (2015). DTM Nigeria Report Round IV. Abuja: International Organisation for Migration (IOM).

[6] INGO FORUM in Nigeria. (2015). Humanitarian Situation in North Eastern Nigeria. Abuja: INGO FORUM in Nigeria.

[7] World Health Organization \& King's College London (2011). The Humanitarian Emergency Settings Perceived Needs Scale (HESPER): Manual with Scale. Geneva: World Health Organization.

[8] The Sphere Project (2004). Humanitarian charter and minimum standards in disaster response. Geneva: The Sphere Project

[9] Inter-Agency Standing Committee (2007). IASC Guidelines on Mental health and psychosocial support in emergency settings. Retrieved on August 4th, 2016 from: www.http://icn.ch/IASC_MHPSS_guidelines.pdf 